\title{
Prevalence of hepatitis- $C$ virus genotypes and potential transmission risks in Malakand Khyber Pakhtunkhwa, Pakistan
}

Nausheen Nazir ${ }^{1}$, Muhammad Rasul Jan², Amjad Ali ${ }^{3 *}$, Muhammad Asif ${ }^{4}$, Muhammad Idrees ${ }^{3,5}$, Mohammad Nisar $^{1 *}$, Muhammad Zahoor ${ }^{6}$ and Naser M. Abd El-Salam

\begin{abstract}
Background: Hepatitis C virus (HCV) is a leading cause of chronic liver disease and frequently progresses towards liver cirrhosis and Hepatocellular Carcinoma (HCC). This study aimed to determine the prevalence of HCV genotypes and their association with possible transmission risks in the general population of Malakand Division.

Methodology: Sum of 570 serum samples were collected during March 2011 to January 2012 from suspected patients visited to different hospitals of Malakand. The suspected sera were tested using qualitative PCR and were then subjected to molecular genotype specific assay. Quantitative PCR was also performed for determination of pre-treatment viral load in confirmed positive patients.

Results: Out of 570 serum samples 316 sera were seen positive while 254 sera were found negative using qualitative PCR. The positive samples were then subjected to genotyping assay out of 316, type-specific PCR fragments were seen in 271 sera while 45 samples were found untypable genotypes. Genotype 3a was seen as a predominant genotype (63.3\%) with a standard error of $\pm 2.7 \%$. Cramer's V statistic and Liklihood-Ratio statistical procedures are used to measure the strength and to test the association, respectively, between the dependent variable, genotype, and explanatory variables (e.g. gender, risk, age and area/districts). The dependent variable, genotype, is observed statistically significant association with variable risk factors. This implies that the genotype is highly dependent on how the patient was infected. In contrast, the other covariates, for example, gender, age, and district (area) no statistical significant association are observed. The association between gender-age indicates that the mean age of female was older by $10.5 \pm 2.3$ years with 95\% confidence level using $t$-statistic.

Conclusion: It was concluded from the present study that the predominant genotype was $3 a$ in the infected population of Malakand. This study also highlights the high prevalence rate of untypable genotypes which an important issue of health care setup in Malakand and create complications in therapy of infected patients. Major mode of HCV transmission is multiple uses and re-uses of needles/injections.
\end{abstract}

Trial registration: ISRCTN ISRCTN73824458. Registered: 28 September 2014

Keywords: HCV, Genotypes potential, Risks factors, Distribution patterns, Malakand

\footnotetext{
*Correspondence: amjad.camb@pu.edu.pk; mnshaalpk@yahoo.com

${ }^{3}$ Centre for Applied Molecular Biology, University of the Punjab, 87-West

Canal Bank Road Thokar Niaz Baig, Lahore, Pakistan

'Department of Botany, University of Malakand, Chakdara Dir (L), Khyber

Pakhtunkhwa, Pakistan

Full list of author information is available at the end of the article
} 


\section{Background}

Hepatitis C (HCV) is an enveloped RNA virus that was firstly discovered in 1989 having $9.6 \mathrm{~Kb}$ genome flanked at both ends by untranslated regions (5 'UTR and 3' UTR). The HCV genome encodes 3008-3037 amino acids of single polyprotein and processed post translationally produce three distinct structural proteins and six non-structural proteins [1].

An estimated $70 \%$ to $85 \%$ of $\mathrm{HCV}$ patients are likely to develop chronic hepatitis, and up to $30 \%$ of these cases progress towards liver cirrhosis [2]. In year 2013, hepatitis $C$ was the foremost cause of 1.46 million deaths worldwide and 7.2 million deaths were expected from the years 2015-2030 [3]. An estimated 130-170 million world's population is chronically infected with hepatitis $\mathrm{C}$, while highest prevalence was observed in Asia and Africa [4]. The distribution pattern of hepatitis $C$ is inconsistent from 4\%-12\% in Asia-pacific regions [5, 6]. About 10 million people have been infected with $\mathrm{HCV}$ in Pakistan [7] and the prevalence rate is $4 \%$ [8]. In China, the prevalence rate ranged from $1 \%$ to $31.86 \%$ depends on its regions of lowest and highest endemic cities [9] while the prevalence rate is $1.8 \%$ in Saudi Arabia [10].

World Health Organization (WHO) organized the first Global Health Sector Strategy (GHSS), 2016-2021, for the prevention and control of viral hepatitis. GHSS would try to stop the expected 7.1 million HCV linked deaths during years 2015-2030 and would achieve the health targets of the 2030 Agenda for Sustainable Development to combat viral hepatitis [11].

$\mathrm{HCV}$ is attributed $27 \%$ cirrhosis and $25 \%$ HCC globally [12] and is the major cause of liver transplantation [13].

$\mathrm{HCV}$ is classified into six major genotypes on the basis of nucleotide heterogeneity. Genotypes 1 and 3 are circulating predominantly across the globe. In Pakistan genotype 3 is the predominant genotype with subtype $3 a$ and 3b circulating with same pattern in males and females [14-17]. Genotype 4 is more prevalent in North Africa and Middle East while in the Hong Kong and South Africa genotypes 5 and 6 are circulating [14].

The common route of HCV transmission in developing country is the re-uses of needles/syringes and unsafe injections $[17,18]$. The improper sterilized medical apparatus, unsafe blood transfusion and re-uses of needles/syringes and unsafe injections causes an estimated of 2 to 5 million HCV infections [19]. The observed risks factors for HCV transmission in Pakistan were including uses \& re-uses of needles/injections unsafe injections, dental procedures, surgeries (major/minor), blood transfusion, barbers, piercing instruments and about $1 \%$ due to vertical transmission $[20,21]$. The reported literatures from Pakistan have shown the prevalence of $\mathrm{HCV}-3 \mathrm{a}$ infections in patients who have received multiple unsafe injections by untrained health practitioners mainly in rural areas [21-25].
In Pakistan many reported studies are available on the prevalence of HCV genotypes and their possible routes of transmission in various districts/cities [7, 14-17, 21, 22, 25-27]. However no such type of study is documented on the prevalence of $\mathrm{HCV}$ genotypes and their association with covariates i.e. age, gender, possible routes of transmission in Malakand Division, Khyber Pakhtunkhwa (KP). So this study aimed to determine the prevalence of different HCV genotypes and their possible routes of transmission in different districts of Malakand, KP, Pakistan.

\section{Materials and methods Blood sampling}

Sum of 570 blood samples were collected from suspected patients visited to different hospitals of Malakand $\mathrm{KP}$. Informed consent was taken in written form from each patient including, demographic characteristic, age, district, risk factor and estimated time of infection along with complete address and phone numbers.

\section{HCV RNA qualitative and quantitative PCRs}

Blood samples were used for qualitative analysis of HCV-RNA as described previously [28]. Total RNA from the suspected patient's sera $(100 \mu \mathrm{l})$ was extracted using Quigen RNA extraction kit. RT-PCR was used for the detection of HCV-RNA. $20 \mu$ reaction mix was used for Nested PCR using Taq DNA-polymerase (Fermentas, Technologies, USA) and products were visualized under UV light using "Uvitec" gel documentation system on $2 \%$ agarose gel.

HCV RNA was quantified in all qualitative PCR positive sera using Smart Cycler-II Real-time PCR (Cepheid, Calif, and Sunnyvale, USA) using HCV-RNA quantification kits (Sacace, Biotechnologies, Italy). The Smart Cycler-II PCR undergoes amplification and identification at the same instant with Taq-Man technology (Applied Biosystems, Calif, Foster City) through fluorescent probes following each replicating cycle. The lower detection limit was $250 \mathrm{IU} / \mathrm{mL}$ and upper detection limit was $5.0 \times 108 \mathrm{IU} / \mathrm{mL}$, respectively. Samples yielding values above the upper limit were diluted 100-fold, retested and the obtained values were multiplied by this dilution factor to get the actual HCV RNA concentration in international units (IU) per $\mathrm{mL}$.

\section{HCV genotyping}

The qualitative PCR positive sera were subjected to $\mathrm{HCV}$ genotyping by using type-specific HCV genotyping procedure as described previously [26]. Briefly, $10 \mu \mathrm{l}$ (50 ng) HCV-RNA was reverse transcribed into cDNA at $37{ }^{\circ} \mathrm{C}$ for $50 \mathrm{~min}$. Two $\mu \mathrm{l}$ of synthesized cDNA was utilized for PCR amplification of 470-bp region from HCV 5'NCR along with core region by 1 st round PCR amplification. The amplified 1st round PCR product was 
subjected to two 2nd rounds of nested PCR amplifications. Two reaction mixes were made, 1st reaction with mix-A primers set and the 2nd reaction with mix-B primers set in a reaction volume of $10 \mu \mathrm{l}$. Mix-A had specific genotype primers set for $1 \mathrm{a}, 1 \mathrm{~b}, 1 \mathrm{c}, 3 \mathrm{a}, 3 \mathrm{c}$ and 4 genotypes and mix-B contained specific genotype primers set for $2 \mathrm{a}, 2 \mathrm{c}, 3 \mathrm{~b}, 5 \mathrm{a}$ and $6 \mathrm{a}$.

\section{Statistical analysis}

SPSS version 17.0 for Windows was used for the analysis of data and summary statistics. The results for all variables were set in the form of rates (\%). T-test is used to test the equality of the two proportions, whereas, the Chi Square tests is used to test the equality of more than two proportions. Further, Chi-Square test, LogLikelihood Ratio test (LR) and Cramer's V statistics were applied to test out the significance of association among the categorical variables $[29,30]$. The level of significance is set as 0.05 , therefore, if any $p$-value observed less than 0.05 was considered as statistical significance.

\section{Results}

Out of 570 blood samples 316 samples were seen positive while 254 found negative using qualitative PCR. The qualitative PCR positive samples were subjected to genotyping assay out of 316 type-specific PCR fragments were seen in 271 serum samples whereas 45 samples were found with untypable genotypes as no genotypespecific band was seen in these samples.

Distribution breakup of HCV infected population was 49 (15.5\%), 96 (30.4\%), 61(19.3\%), 52 (16.5\%) and 58(18.4\%) from Batkhela, Swat, Bunir, Shangla and Dir (lower) districts respectively. Fig. 1 shows a typical agarose gel showing different HCV genotype-specific bands (HCV-1a \& HCV-3a).

\section{Gender wise distribution of HCV genotypes among the studied patients}

Table 1 demonstrates the cross-tabulation of HCV genotype and gender. Out of $316 \mathrm{HCV}$ patients, males subjects were $171(54.1 \%)$ and females were 145(45.9\%).
Each cell of the table contained the actual frequency, the percentage prevalence within the genotypes and gender. In this study the genotype " $3 \mathrm{a}$ " is observed most frequently in both male and female patients. Moreover, no significant changes were observed by comparing the proportions of male and female for each category of the genotype, as all the $p$ values were greater than 0.05 (Table 1). For this purpose we used the t-test to test the hypothesis of the female percentage equal to $50 \%$.

\section{Distribution of HCV genotypes in different districts of Malakand}

The cross-tabulation of the two categorical variables, genotype and district are provided in the Table 2 in which no statistical evidence is observed to confirm the strong association.

In contrast, we are able to compare the prevalence of given genotype, i.e. "3a", within a district with that of the prevalence of the same genotype within another district. For example, it can be observed that the frequency distribution of genotype within each district is with highest frequency percentage of the common type " $3 a$ " in all districts. It can be seen from Table 2, the percentages of "3a" for district Batkhela, Bunir, Dir (L), Shangla, and Swat are $69.4 \%, 68.9 \%, 58.6 \%, 59.6 \%$ and $61.5 \%$ respectively.

\section{Distribution of HCV genotypes in different age groups}

The count summaries of HCV genotypes in various age groups are provided in the Table 3 . No statistical significance difference is observed between $\mathrm{HCV}$ genotypes and different age groups. The $p$-value to test the significance of the association is observed as 0.484 using the LR test. The detailed summary of the tests is provided in the Table 4. Similar to other categorical variable, the cross tabulation of genotype and age group was also performed. In contrast, the prevalence of the given genotype within age group can possibly be compared with that of the prevalence of the same genotype within another age group. For example, it can be observed from Table 3 that the distributions of genotype within each age

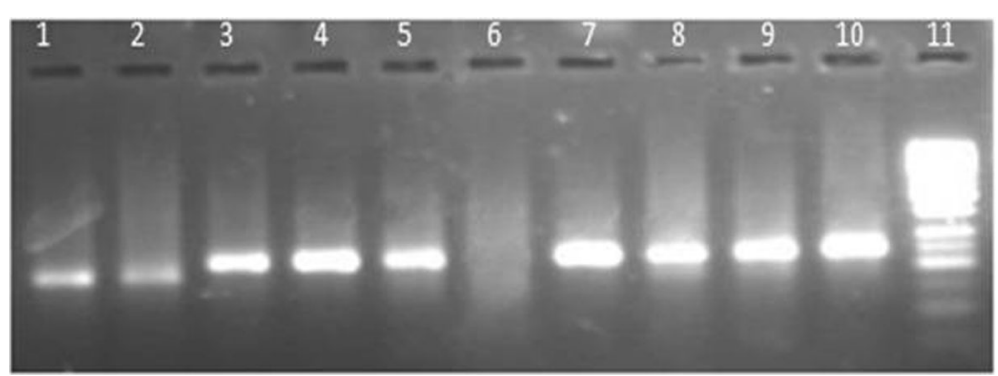

Fig. 1 Agarose gel (2\%) electrophoresis illustrates results for genotyping of HCV specimens by multiplex PCR as prescribed previously [26]. Lanes 1, 2 showing genotype 1a (129-bp); Lanes 3, 4, 5 \&7-10 showing genotype 3a (258-bp); Lane 6 shows negative control and Lane 11 contain 50-bp DNA ladder marker 
Table 1 Gender wise distribution of HCV genotypes among the studied patients

\begin{tabular}{|c|c|c|c|c|c|c|c|c|c|}
\hline \multirow[b]{2}{*}{ Gender } & & & \multicolumn{6}{|c|}{ Genotype } & \multirow[t]{2}{*}{ Total } \\
\hline & & & $1 a$ & $1 b$ & $3 a$ & $3 b$ & Mixed & Untypable & \\
\hline & Female & Count & 4 & 6 & 91 & 11 & 10 & 23 & 145 \\
\hline & & $\%$ prevalence within Gender & $2.8 \%$ & $4.1 \%$ & $62.8 \%$ & $7.6 \%$ & $6.9 \%$ & $15.9 \%$ & $100.0 \%$ \\
\hline & & $\%$ prevalence within Genotype & $26.7 \%$ & $66.7 \%$ & $45.5 \%$ & $44.0 \%$ & $45.5 \%$ & $51.1 \%$ & $45.9 \%$ \\
\hline & Male & Count & 11 & 3 & 109 & 14 & 12 & 22 & 171 \\
\hline & & $\%$ prevalence within Gender & $6.4 \%$ & $1.8 \%$ & $63.7 \%$ & $8.2 \%$ & $7.0 \%$ & $12.9 \%$ & $100.0 \%$ \\
\hline & & $\%$ prevalence within Genotype & $73.3 \%$ & $33.3 \%$ & $54.5 \%$ & $56.0 \%$ & $54.5 \%$ & $48.9 \%$ & $54.1 \%$ \\
\hline \multirow[t]{3}{*}{ Total } & & Count & 15 & 9 & 200 & 25 & 22 & 45 & 316 \\
\hline & & $\%$ prevalence within Gender & $4.7 \%$ & $2.8 \%$ & $63.3 \%$ & $7.9 \%$ & $7.0 \%$ & $14.2 \%$ & $100.0 \%$ \\
\hline & & $p$-value & 0.118 & 0.508 & 0.229 & 0.69 & 0.83 & 0.99 & $100.0 \%$ \\
\hline
\end{tabular}

Gender * Genotype Cross tabulation, The $p$-values are for comparing proportion of Female with $50 \%$

group with common genotype 3a. For example, the percentages of the 3 a genotype within age-group for age categories 10-20, 20-30, 30-40, 40-50, 50-60, and 60+ are $56.5 \%, 65.4 \%, 63.9 \%, 61.5 \%, 60.0$, and $100 \%$. Regarding the highest percentage of the $60+$ category is due to limited data as only five patients are with the age more than 60 years that all have infected with $3 \mathrm{a} \mathrm{HCV}$ genotype.

\section{HCV genotypes and its association with different risk factors}

The possible risk factors correlated with HCV genotypes are represented in Table 5 \& Fig. 2. The potential risk factors are Barber Shop 60(19.0\%), Blood Transfusion 51(16.1\%), Medical Surgeries 77(20.3\%), uses and re-uses of needles/syringes $106(33.5 \%)$, and others were unknown 22(7.0\%). The LR test suggests that there is strong evidence in the sample data that there exist statistically significant association between variable of interest, genotype and risk-factor. The $p$-value as described in the Table 4 is observed as smaller than our pre-defined level of significance, 0.05. Table 6 describes the count summary of the sample data, the proportion along with the standard error of the proportion. Further, the mean age along with standard error of each category are also

Table 2 Prevalence of HCV genotypes in different geographical regions of Malakand

\begin{tabular}{|c|c|c|c|c|c|c|c|c|c|}
\hline & & & \multicolumn{6}{|c|}{ Genotype } & \multirow[t]{2}{*}{ Total } \\
\hline & & & $1 \mathrm{a}$ & $1 b$ & $3 a$ & $3 b$ & Mixed & Untypable & \\
\hline \multirow[t]{15}{*}{ District } & \multirow[t]{3}{*}{ Batkhela } & Count & 2 & 1 & 34 & 5 & 2 & 5 & 49 \\
\hline & & $\%$ prevalence within District & $4.1 \%$ & $2.0 \%$ & $69.4 \%$ & $10.2 \%$ & $4.1 \%$ & $10.2 \%$ & $100.0 \%$ \\
\hline & & $\%$ prevalence within Genotype & $13.3 \%$ & $11.1 \%$ & $17.0 \%$ & $20.0 \%$ & $9.1 \%$ & $11.1 \%$ & $15.5 \%$ \\
\hline & \multirow[t]{3}{*}{ Bunir } & Count & 0 & 0 & 42 & 2 & 4 & 13 & 61 \\
\hline & & $\%$ prevalence within District & $.0 \%$ & $.0 \%$ & $68.9 \%$ & $3.3 \%$ & $6.6 \%$ & $21.3 \%$ & $100.0 \%$ \\
\hline & & $\%$ prevalence within Genotype & $.0 \%$ & $.0 \%$ & $21.0 \%$ & $8.0 \%$ & $18.2 \%$ & $28.9 \%$ & $19.3 \%$ \\
\hline & \multirow[t]{3}{*}{ Dir(Lower) } & Count & 4 & 3 & 34 & 7 & 5 & 5 & 58 \\
\hline & & $\%$ prevalence within District & $6.9 \%$ & $5.2 \%$ & $58.6 \%$ & $12.1 \%$ & $8.6 \%$ & $8.6 \%$ & $100.0 \%$ \\
\hline & & $\%$ prevalence within Genotype & $26.7 \%$ & $33.3 \%$ & $17.0 \%$ & $28.0 \%$ & $22.7 \%$ & $11.1 \%$ & $18.4 \%$ \\
\hline & \multirow[t]{3}{*}{ Shangla } & Count & 3 & 4 & 31 & 5 & 3 & 6 & 52 \\
\hline & & $\%$ prevalence within District & $5.8 \%$ & $7.7 \%$ & $59.6 \%$ & $9.6 \%$ & $5.8 \%$ & $11.5 \%$ & $100.0 \%$ \\
\hline & & $\%$ prevalence within Genotype & $20.0 \%$ & $44.4 \%$ & $15.5 \%$ & $20.0 \%$ & $13.6 \%$ & $13.3 \%$ & $16.5 \%$ \\
\hline & \multirow[t]{3}{*}{ Swat } & Count & 6 & 1 & 59 & 6 & 8 & 16 & 96 \\
\hline & & $\%$ prevalence within District & $6.3 \%$ & $1.0 \%$ & $61.5 \%$ & $6.3 \%$ & $8.3 \%$ & $16.7 \%$ & $100.0 \%$ \\
\hline & & $\%$ prevalence within Genotype & $40.0 \%$ & $11.1 \%$ & $29.5 \%$ & $24.0 \%$ & $36.4 \%$ & $35.6 \%$ & $30.4 \%$ \\
\hline \multirow[t]{3}{*}{ Total } & & Count & 15 & 9 & 200 & 25 & 22 & 45 & 316 \\
\hline & & $\%$ within District & $4.7 \%$ & $2.8 \%$ & $63.3 \%$ & $7.9 \%$ & $7.0 \%$ & $14.2 \%$ & $100.0 \%$ \\
\hline & & $\%$ within Genotype & $100.0 \%$ & $100.0 \%$ & $100.0 \%$ & $100.0 \%$ & $100.0 \%$ & $100.0 \%$ & $100.0 \%$ \\
\hline
\end{tabular}


Table 3 Prevalence of HCV genotypes in different age groups of HCV patients

\begin{tabular}{|c|c|c|c|c|c|c|c|c|c|}
\hline & & & \multicolumn{6}{|c|}{ Genotype } & \multirow[t]{2}{*}{ Total } \\
\hline & & & $1 a$ & $1 \mathrm{~b}$ & $3 a$ & $3 b$ & Mixed & Untypable & \\
\hline \multirow[t]{18}{*}{ Age group } & $10-20$ & Count & 0 & 0 & 13 & 2 & 0 & 8 & 23 \\
\hline & & $\%$ prevalence within Age group & $.0 \%$ & $.0 \%$ & $56.5 \%$ & $8.7 \%$ & $.0 \%$ & $34.8 \%$ & $100.0 \%$ \\
\hline & & $\%$ prevalence within Genotype & $.0 \%$ & $.0 \%$ & $6.5 \%$ & $8.0 \%$ & $.0 \%$ & $17.8 \%$ & $7.3 \%$ \\
\hline & $20-30$ & Count & 4 & 1 & 53 & 5 & 7 & 11 & 81 \\
\hline & & $\%$ prevalence within Age group & $4.9 \%$ & $1.2 \%$ & $65.4 \%$ & $6.2 \%$ & $8.6 \%$ & $13.6 \%$ & $100.0 \%$ \\
\hline & & $\%$ prevalence within Genotype & $26.7 \%$ & $11.1 \%$ & $26.5 \%$ & $20.0 \%$ & $31.8 \%$ & $24.4 \%$ & $25.6 \%$ \\
\hline & $30-40$ & Count & 7 & 3 & 62 & 8 & 5 & 12 & 97 \\
\hline & & $\%$ prevalence within Age group & $7.2 \%$ & $3.1 \%$ & $63.9 \%$ & $8.2 \%$ & $5.2 \%$ & $12.4 \%$ & $100.0 \%$ \\
\hline & & $\%$ prevalence within Genotype & $46.7 \%$ & $33.3 \%$ & $31.0 \%$ & $32.0 \%$ & $22.7 \%$ & $26.7 \%$ & $30.7 \%$ \\
\hline & $40-50$ & Count & 4 & 4 & 40 & 5 & 6 & 6 & 65 \\
\hline & & $\%$ prevalence within Age group & $6.2 \%$ & $6.2 \%$ & $61.5 \%$ & $7.7 \%$ & $9.2 \%$ & $9.2 \%$ & $100.0 \%$ \\
\hline & & $\%$ prevalence within Genotype & $26.7 \%$ & $44.4 \%$ & $20.0 \%$ & $20.0 \%$ & $27.3 \%$ & $13.3 \%$ & $20.6 \%$ \\
\hline & $50-60$ & Count & 0 & 1 & 27 & 5 & 4 & 8 & 45 \\
\hline & & $\%$ prevalence within Age group & $.0 \%$ & $2.2 \%$ & $60.0 \%$ & $11.1 \%$ & $8.9 \%$ & $17.8 \%$ & $100.0 \%$ \\
\hline & & $\%$ prevalence within Genotype & $.0 \%$ & $11.1 \%$ & $13.5 \%$ & $20.0 \%$ & $18.2 \%$ & $17.8 \%$ & $14.2 \%$ \\
\hline & $60+$ & Count & 0 & 0 & 5 & 0 & 0 & 0 & 5 \\
\hline & & $\%$ prevalence within Age group & $.0 \%$ & $.0 \%$ & $100.0 \%$ & $.0 \%$ & $.0 \%$ & $.0 \%$ & $100.0 \%$ \\
\hline & & $\%$ prevalence within Genotype & $.0 \%$ & $.0 \%$ & $2.5 \%$ & $.0 \%$ & $.0 \%$ & $.0 \%$ & $1.6 \%$ \\
\hline \multirow[t]{3}{*}{ Total } & & Count & 15 & 9 & 200 & 25 & 22 & 45 & 316 \\
\hline & & $\%$ prevalence within Age group & $4.7 \%$ & $2.8 \%$ & $63.3 \%$ & $7.9 \%$ & $7.0 \%$ & $14.2 \%$ & $100.0 \%$ \\
\hline & & \% prevalence within Genotype & $100.0 \%$ & $100.0 \%$ & $100.0 \%$ & $100.0 \%$ & $100.0 \%$ & $100.0 \%$ & $100.0 \%$ \\
\hline
\end{tabular}

provided. Regarding the distribution of the genotype, the variable of interest in this study, it can be observed that the most common genotype in the sample is $3 \mathrm{a}$ accounted $63.3 \%$ patients with standard error $2.71 \%$. It can also be noticed that there were $(14.2 \pm 1.96) \%$ patients whom genotype was untypable.

In addition to the test results, the cross-tabulation summary is also provided in the Table 5 . It can be observed by visual inspection that the distribution of the genotype changes with respect to changes in Risk factor. For example, a total 51 patients were infected because of blood transfusion, out of which 23 (45.1\%) were genotyped 3a. In contrast, this percentage increased to $83.3 \%$ if the patients are infected due to reuses of needles and unsafe injection.

\section{HCV RNA viral titers}

Pretreatment viral titer was classified of the typable and untypable genotypes into three categories based on its level such as low $(<60,0000 \mathrm{IU} / \mathrm{ml})$, intermediate $(60$, 0000-80, $00000 \mathrm{IU} / \mathrm{ml})$ and high $(>80,00000 \mathrm{IU} / \mathrm{ml})$ viral titer. All the HCV RNA positive samples of current study were genotyped using reported PCR genotyping assay [26]. Base line $\mathrm{HCV}$ viral titer for typable genotypes was low $(<60,0000 \mathrm{IU} / \mathrm{ml})$ and intermediate $(60$,
0000 to $80,00000 \mathrm{IU} / \mathrm{ml}$ ) while the viral titer of untypable genotype was seen high $(>80,00000 \mathrm{IU} / \mathrm{ml})$, so untypability was not due to low viral titer but due to changes in genotypes sequences.

\section{Discussion}

Malakand division is situated in the Khyber Pukhtunkhwa region of Pakistan lies at a known historic position and acts as a gateway to Chitral, Dir, Baja War and Swat. The present study aimed to determine the distribution of $\mathrm{HCV}$ genotypes and their potential transmission risks in

Table 4 Summary of statistical tests/strength of association among genotypes vs. gender, risk factor, district and age group in 316 HCV suspected patients

\begin{tabular}{|c|c|c|c|c|}
\hline & \multicolumn{4}{|l|}{ Method } \\
\hline & \multicolumn{2}{|c|}{ Likelihood-Ratio test } & \multicolumn{2}{|c|}{ Strength of Association } \\
\hline & LR-Statistic & $p$-value & Cramer's V & $p$-value \\
\hline Genotype * Gender & $4.462(5)$ & 0.485 & 0.117 & 0.501 \\
\hline Genotype ${ }^{*}$ Risk factor & $64.1(20)$ & 0.000 & 0.225 & $0.000^{*}$ \\
\hline Genotype * District/area & $26.61(20)$ & 0.147 & 0.135 & 0.290 \\
\hline Genotype ${ }^{*}$ Age group & 29.25 (25) & 0.254 & 0.125 & 0.484 \\
\hline
\end{tabular}

Degree of freedom are mentioned in the bracket along with the test statistic * Highly significant 
Table 5 Risk factors assessment for HCV infection

\begin{tabular}{|c|c|c|c|c|c|c|c|c|c|}
\hline \multirow{2}{*}{ Risk factors } & & & \multicolumn{6}{|c|}{ Genotype } & \multirow[t]{2}{*}{ Total } \\
\hline & & & $1 \mathrm{a}$ & $1 b$ & $3 a$ & $3 b$ & Mixed & Untypable & \\
\hline & \multirow[t]{3}{*}{ Barbers } & Count & 6 & 1 & 31 & 3 & 5 & 14 & 60 \\
\hline & & $\%$ prevalence within Risk factor & $10.0 \%$ & $1.7 \%$ & $51.7 \%$ & $5.0 \%$ & $8.3 \%$ & $23.3 \%$ & $100.0 \%$ \\
\hline & & $\%$ prevalence within Genotype & $40.0 \%$ & $11.1 \%$ & $15.5 \%$ & $12.0 \%$ & $22.7 \%$ & $31.1 \%$ & $19.0 \%$ \\
\hline & \multirow[t]{3}{*}{ Blood transfusion } & Count & 3 & 4 & 23 & 6 & 11 & 4 & 51 \\
\hline & & $\%$ prevalence within Risk factor & $5.9 \%$ & $7.8 \%$ & $45.1 \%$ & $11.8 \%$ & $21.6 \%$ & $7.8 \%$ & $100.0 \%$ \\
\hline & & $\%$ prevalence within Genotype & $20.0 \%$ & $44.4 \%$ & $11.5 \%$ & $24.0 \%$ & $50.0 \%$ & $8.9 \%$ & $16.1 \%$ \\
\hline & \multirow[t]{3}{*}{ Medical surgeries } & Count & 5 & 2 & 45 & 9 & 2 & 14 & 77 \\
\hline & & $\%$ prevalence within Risk factor & $6.5 \%$ & $2.6 \%$ & $58.4 \%$ & $11.7 \%$ & $2.6 \%$ & $18.2 \%$ & $100.0 \%$ \\
\hline & & $\%$ prevalence within Genotype & $33.3 \%$ & $22.2 \%$ & $22.5 \%$ & $36.0 \%$ & $9.1 \%$ & $31.1 \%$ & $24.4 \%$ \\
\hline & \multirow[t]{3}{*}{ Needles/syringes } & Count & 0 & 2 & 88 & 5 & 4 & 7 & 106 \\
\hline & & $\%$ prevalence within Risk factor & $0.0 \%$ & $1.9 \%$ & $83.0 \%$ & $4.7 \%$ & $3.8 \%$ & $6.6 \%$ & $100.0 \%$ \\
\hline & & $\%$ prevalence within Genotype & $0.0 \%$ & $22.2 \%$ & $44.0 \%$ & $20.0 \%$ & $18.2 \%$ & $15.6 \%$ & $33.5 \%$ \\
\hline & \multirow[t]{6}{*}{ Unknown } & Count & 1 & 0 & 14 & 2 & 0 & 5 & 22 \\
\hline & & $\%$ prevalence within Risk factor & $4.5 \%$ & $0.0 \%$ & $63.6 \%$ & $9.1 \%$ & $0.0 \%$ & $22.7 \%$ & $100.0 \%$ \\
\hline & & $\%$ prevalence within Genotype & $6.7 \%$ & $0.0 \%$ & $7.0 \%$ & $8.0 \%$ & $0.0 \%$ & $11.11 \%$ & $7.0 \%$ \\
\hline & & Total count & 15 & 9 & 200 & 25 & 22 & 45 & 316 \\
\hline & & $\%$ prevalence within Risk factor & $4.7 \%$ & $2.8 \%$ & $63.3 \%$ & $7.9 \%$ & $7.0 \%$ & $14.2 \%$ & $100.0 \%$ \\
\hline & & $p$-value for within Genotype risk comparison & $N / A^{a}$ & $N / A^{a}$ & 0.000 & 0.199 & $0.042^{\mathbf{b}}$ & 0.044 & $100.0 \%$ \\
\hline
\end{tabular}

${ }^{a}$ Insufficient data, therefore, Chi-Square test of equal proportion cannot be applied

b The category 'Unkown' is ignored while the calculation of the Chi-Square statistic and corresponding $P$-value

Malakand. The data was categorized for analysis in terms of gender, risk factors, age groups and locality. In the present study correlation of $\mathrm{HCV}$ genotypes were reported with gender. It was confirmed that there was no variation of HCV genotypes distribution among both sexes all the genotypes were circulated with the same pattern in male and female patients. The same results were also demonstrated by previous reported studies and confirmed that there is no difference in distribution of HCV genotypes between male and female patients $[15,31]$. But our results were contradicted from previous reported study that $\mathrm{HCV}$ genotypes were not distributed with same pattern where as HCV genotype 1 is circulating in male subjects while genotype 4 in female patients [32].

In our findings the frequently circulated genotype was 3a similar results was also reported by previous studies

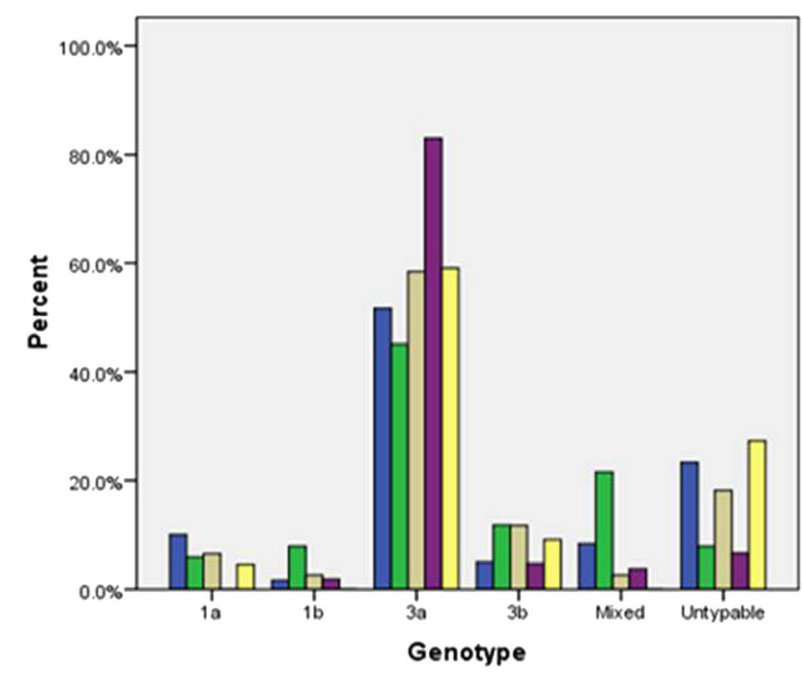

Risk factors

Barber shop

Blood Transfusion Medical surgries Needles/Syringes Unknown

Fig. 2 Risk factors assessment of genotypes for HCV infection 
Table 6 The case summary of 316 patients on the categorical variables information, reported from Malakand division Pakistan

\begin{tabular}{|c|c|c|c|c|c|}
\hline \multicolumn{3}{|l|}{ Categorical variables } & \multirow{2}{*}{$\frac{N}{15}$} & \multirow{2}{*}{$\frac{\text { Percent } \pm \text { S.E }}{04.7 \pm 1.19}$} & \multirow{2}{*}{$\frac{\text { Mean Age } \pm \text { SE }}{34.20 \pm 2.279}$} \\
\hline Variable of Interest & Genotype & $1 a$ & & & \\
\hline & & $1 b$ & 9 & $02.8 \pm 0.93$ & $42.44 \pm 3.392$ \\
\hline & & $3 a$ & 200 & $63.3 \pm 2.71$ & $37.56 \pm 0.906$ \\
\hline & & $3 b$ & 25 & $7.9 \pm 1.52$ & $38.88 \pm 2.444$ \\
\hline & & Mixed & 22 & $7.0 \pm 1.43$ & $39.55 \pm 2.371$ \\
\hline & & Untypable & 45 & $14.2 \pm 1.96$ & $35.42 \pm 2.018$ \\
\hline \multirow[t]{13}{*}{ Risk factors } & Gender & Female & 145 & $45.9 \pm 2.80$ & $43.17 \pm 1.036$ \\
\hline & & Male & 171 & $54.1 \pm 2.80$ & $32.65 \pm 0.797$ \\
\hline & Risk factors & Barber shop & 60 & $19.0 \pm 2.21$ & $30.23 \pm 0.814$ \\
\hline & & Blood Transfusion & 51 & $16.1 \pm 2.07$ & $29.29 \pm 1.667$ \\
\hline & & Medical surgeries & 77 & $24.4 \pm 2.42$ & $32.45 \pm 1.044$ \\
\hline & & Needles/Syringes & 106 & $33.5 \pm 2.65$ & $44.80 \pm 0.810$ \\
\hline & & Unknown & 22 & $07.0 \pm 1.43$ & $58.50 \pm 2.343$ \\
\hline & District & Batkhela & 49 & $15.5 \pm 2.03$ & $25.35 \pm 1.078$ \\
\hline & & Bunir & 61 & $19.3 \pm 2.22$ & $38.00 \pm 1.146$ \\
\hline & & Dir(Lower) & 58 & $18.4 \pm 2.18$ & $50.17 \pm 1.509$ \\
\hline & & Shangla & 52 & $16.5 \pm 2.09$ & $43.33 \pm 1.457$ \\
\hline & & Swat & 96 & $30.4 \pm 2.59$ & $32.50 \pm 0.944$ \\
\hline & Total & & 316 & & $37.48 \pm 0.706$ \\
\hline
\end{tabular}

The Standard Errors (S.E) of the corresponding sample proportions (expressed in percentages) and mean age are determine by the property of the sampling distribution

conducted in different districts/towns of Khyber Pakhtunkhwa and confirmed that the predominant genotype was 3 a $[15,16,21,27,33-36]$. Our results are also in accordance with another study conducted in Lahore, showed the predominant prevalence of genotype 3a [37]. Another epidemiological study was also conducted in seven different regions of Baluchistan province of Pakistan and reported that $3 \mathrm{a}$ was the predominant genotype [38]. Available studies on the distribution of HCV genotypes in different districts/areas of Pakistan have confirmed that predominant genotype was $3 \mathrm{a}[18,20-23,25,31,37,39$, 40]. So the present study confirmed that in general population of Malakand HCV type 3a-infected patients are high as compared to other genotypes.

Our results were also similar to our neighboring country like India and in far away Asian country like Nepal and confirmed that most prevalent circulating in these countries was type 3a [41] but dissimilar to Americas, Europe and Japan where 1 and 2 are commonly circulating genotypes [42]. In North Africa and Middle East genotype 4 is prevalent while in Hong Kong and South Africa 5 and 6 genotypes were present [14]. In our study genotypes 4, 5 and 6 were not identified, also confirmed by other studies that these genotypes are not circulating in this region or partially absent from Pakistan $[15,34]$.

Findings of the this study confirmed that there is no geographical variation among the distribution of $\mathrm{HCV}$ genotypes in Malakand all the genotypes were distributed, with same pattern in all districts and similar results were also confirmed by another reported study that all the genotypes were circulating with the same pattern in different regions of Pakistan [15, 40].

An interesting finding of our study is the number of untypable genotypes that produced no genotype-specific PCR fragments in our genotyping assay [26]. All the untypable genotypes had sufficient viral titer indicating that the untypability was not due to low HCV levels. Because untypable $\mathrm{HCV}$ genotypes have also been reported in other studies from Pakistan [34-36], this suggests the presence of new genotypes and/or quasispecies which may present a critical health care issue in Pakistan if there are difficulties in treatment of these patients. As such, there is a need to sequence these untypable HCV samples to determine the cause of this problem and possibly to identify appropriate primers for these potential new sub-genotypes to reduce the number of untypable $\mathrm{HCV}$ genotypes.

The results were further analyzed for different age groups it was investigated from the overall mean age and $S E$ of mean $(37.48 \pm 0.706)$ that the high prevalence of $\mathrm{HCV}$ infection was seen in age group of $\leq 40$ years. Our findings are in agreement with previous published studies that highest frequency of $\mathrm{HCV}$ infection was seen in age group of $\leq 40$ years as compared to $\geq 40$ age 
group which revealed that the general population of this region is alert for early $\mathrm{HCV}$ diagnosis $[15,40]$.

The study was further analyzed to correlate various $\mathrm{HCV}$ genotypes with their potential transmission risks. Statistically significant association is observed between response variable genotype and one covariate risk-factor in the data using the Log likelihood-Ratio test. For example, it can be observed that the highest number of patients, 88 out of 200 infected patients with genotype $3 \mathrm{a}$, was exposed to the multiple uses and reuses of contaminated needles /syringes. However, in contrast no patient was observed with genotype 1a that is infected due to the reuse of the needles/Injections. It was suggested by the previously countrywide reports that $3 \mathrm{a}$ is the common genotype among individuals used contaminated needles/syringes $[14,17,18]$. In Pakistan the utilization of injections per person annually ranged from 8.2-13.6 which is maximum range amongst under developing countries [18]. In regards to the overall distribution of the infected patients with respect to the riskfactor, the highest prevalent risk factor is the reuses of needles/injections that possibly cause to infect $106 \mathrm{pa}-$ tients in out of 316. Similarly, 2nd most prevalent risk factor is a medical/dental surgeries (both major and minor) confirmed that medical experts and dentists used unsterilized surgical instruments and consider main contributors in spreading of HCV infection in healthy population [15, 22]. Exposure to barber shops is also a major risk for $\mathrm{HCV}$ infection reported previously [35, 43]. In our data we also reported that barbers are also contributes in $\mathrm{HCV}$ infection spreading to healthy population because most of the barbers uneducated and reuse contaminated razors/blades for general population of this region/area. Another risk factor is transfusion of blood is accounted $16.1 \%$ in majority of HCV thalassaemic patients who had received blood transfusion many times in life and suggests that blood in that area not screen properly before transfusion and is a major issue for thalassaemic patients and general healthy population.

Limitations of this study: first limitation was the detection of large number of HCV untypable genotypes. The detected HCV untypable samples had sufficient viral titers and required to sequence these samples for identification of exact genotype, but we were unable to sequence these untypable samples because the lack of sequencing facilities in our institution another limitation of our study is the risk factor data is self-reported by patients.

\section{Conclusions}

It is concluded from the current study that $3 \mathrm{a}$ is the most common genotype. The common transmission route is the reuses of needles/syringes and unsafe injections. Further, the statistical dependence of risk factor on the distribution of genotype is observed. However, in contrast, no statistical dependence on covariates, age, gender and district, is identified. Local variation in the circulation of genotypes was not seen in the current study, all the genotypes/subtypes were present with similar pattern in different district/areas of Malakand. A strong campaign should be needed to inform the health care professionals and dispensers of the rural areas to avoid the reuses of needles/syringes and unsafe injections to control further spreading of $\mathrm{HCV}$.

\section{Abbreviations \\ CDNA: Complementra DNA; HCV: Hepatitis C Virus; LR: Log-Likelihood Ratio test; SE: Standard error; UTR: Untranslated Region}

\section{Acknowledgements}

We are thankful to all the clinicians and paramedical staff of the Malakand Division for facilitation.

\section{Funding}

The authors are thankful to the Deanship of Scientific Research, King Saud University, Riyadh, Saudi Arabia, for funding the work through the research group Project no. RGP-210.

\section{Availability of data and materials}

Not applicable.

\section{Authors' contributions}

$\mathrm{NN}$ and AA collected the samples and performed the molecular genotyping analysis. NN searched the literature and drafted the manuscript. MRJ, MN, AA and $\mathrm{MI}$ critically reviewed the manuscript. MA, MZ NMAEIS, performed all statistical analysis and interprets the results. All the authors read and approved the final manuscript.

\section{Ethics approval and consent to participate}

This study was approved by ethical committee of the University.

\section{Consent for publication}

We have obtained written consent from all participants to publish their data.

\section{Competing of interests}

None of the authors have any conflict of interest.

\section{Publisher's Note}

Springer Nature remains neutral with regard to jurisdictional claims in published maps and institutional affiliations.

\section{Author details}

${ }^{1}$ Department of Botany, University of Malakand, Chakdara Dir (L), Khyber Pakhtunkhwa, Pakistan. ${ }^{2}$ Institute of Chemical Sciences, University of Peshawar, Peshawar, Khyber Pakhtunkhwa, Pakistan. ${ }^{3}$ Centre for Applied Molecular Biology, University of the Punjab, 87-West Canal Bank Road Thokar Niaz Baig, Lahore, Pakistan. ${ }^{4}$ Department of Statistics, University of Malakand, Chakdara Dir (L), Khyber Pakhtunkhwa, Pakistan. ${ }^{5}$ Vice Chancellor Hazara University, Mansehra, Pakistan. ${ }^{6}$ Department of Chemistry, University of Malakand, Khyber Pakhtunkhwa, Chakdara Dir (L), Pakistan. ${ }^{7}$ Riyadh Community College, King Saud University, Riyadh 11437, Saudi Arabia.

Received: 12 November 2016 Accepted: 14 August 2017

Published online: 22 August 2017

\section{References}

1. Argentini C, Genovese D, Dettori S, Rapicetta M. HCV genetic variability from quasispecies evolution to genotype classification. Future Microbiol. 2009;4:359-73.

2. Lauer G, Walker B. Hepatitis C virus infection. N Engl J Med. 2001:345:41-52. 3. WHO: Global Health Observatory (online database). 06 May 2016. 
4. Hanafiah K, Groeger J, Flaxman A, Wiersma S. Global epidemiology of hepatitis $C$ virus infection: new estimates of age-specific antibody to HCV seroprevalence. Hepatology. 2013;57(4):42-1333.

5. Takahashi M, Yamada G, Miyamato R, Doi T, Tsuji T. Natural course of chronic hepatitis C. American J Gastroenterology. 1993;88:240-3.

6. Raza S, Mubeen H, Faroogi S. Review: epidemic status of HCV in Pakistan. GlobJof EnginScience and Research Manage. 2015;12:2.

7. Afzal S, Khan Y, Ammar M, Anjum S, Zaidi S. Diagnostically untypable hepatitis C virus variants: it is time to resolve the problem. World J Gastroenterol. 2014;20(46):17690-2.

8. Waheed Y, Shafi T, Safi S, Qadri I. Hepatitis C virus in Pakistan: a systematic review of prevalence, genotypes and risk factors. World J Gastroenterol. 2009;15(45):53-5647.

9. Ruan Y, Qin G, Yin L, Chen K, Qian H, Hao C. Incidence of HIV, hepatitis C and hepatitis $B$ viruses among injection drug users in southwestern China: a 3-year follow-up study. AIDS. 2007;8:39-46.

10. Al-Tawfiq J, Anani A. Profile of viral hepatitis $a, B$, and C in a Saudi Arabian hospital. Med Sci Monit. 2008;14(1):6-52.

11. Prevention and Control of Viral Hepatitis Infection: Framework for Globa Action. 3 April 2016

12. Zaman N, Asad J, Raza A, Raja K, Akhter S, Mahmood M, Mahmood T. Detection of HCV RNA and NS5A protein in peripheral blood mononuclear cells after sustained Virological response may cause viral relapse. Wor J of Gastroenterol. 2015;47(4):981-7.

13. Perz JF, Armstrong GL, Farrington LA, YJF H, Bel BP. The contributions of hepatitis $B$ virus and hepatitis $C$ virus infections to cirrhosis and primary liver cancer worldwide. J Hepatol. 2006:45529-38.

14. Waheed $Y$. Effect of interferon plus ribavirin therapy on hepatitis $C$ virus genotype 3 patients from Pakistan: treatment response, side effects and future prospective. Asian Pacific J of Tropical Med. 2015;14:85-9.

15. Ali A, Nisar M, Ahmad H, Saif N, Idrees M, Bajwa M. Determination of HCV genotypes and viral loads in chronic HCV infected patients of HazaraPakistan. Virol J. 2011;8:466

16. Khan $\mathrm{T}$, Mehr M, Ullah $\mathrm{H}$, Khan $\mathrm{H}$, Iman N. Frequency of hepatitis $\mathrm{C}$ genotypes in the north of Pakistan. Gomal J Med Sci. 2014;12:9-106.

17. Akhtar M, Majeed S, Jamil M, Rehman A. Hepatitis C virus infection among injecting drug users in Lahore,Pakistan:A cross sectional study. Pak J Med Sci. 2016:32(2):373-8

18. Saeed U, Manzoor S. Risk factors associated with transmission of hepatitis $B$ and hepatitis C virus in Pakistan. GlobJof Medi resear Dise. 2014;14:2249-4618.

19. Bosan A, Qureshi H, Bile M, Ahmad I, Hafiz R. A review of hepatitis viral infections in Pakistan National Institute of health. Pak MedResearch CouncWHO. 2010;60:12.

20. Afridi S, Naeem M, Hussain A, Kakar N, Babar M, Ahmad J. Prevalence of hepatitis C virus (HCV) genotypes in Balochistan. Mol Biol Rep. 2009;36: 1511-4.

21. Safi A, Waheed Y, Sadat J, ul Islam S, Salahuddin S, Saeed U, Ashraf M. Molecular study of HCV detection, genotypes and their routes of transmission in north west Frontier Province, Pakistan. Asian Pac J Trop Biomed. 2012;2:532-6.

22. Umar M, Ahmad M, Khurram M, Usman S, Arif M, Adam T, Minhas Z, Arif A, Naeem A, Ejaz K, et al. Hepatitis C in Pakistan: a review of available data. Hepat Mon. 2010;10(3):205-14.

23. Ahmad N, Asgher M, Shafique M, Qureshi J. An evidence of high prevalence of hepatitis C virus in Faisalabad, Pakistan. Saudi Med J. 2007:8(3):5-390.

24. Alam S, Ahmad N, Khan M, Mustafa G, Al Mamun A, Mashud G. Seroprevalence of hepatitis C virus infection among health care workers. Bangladesh College of Physicians and Surgeons. 2007;25(3):126-9.

25. Khan N, Akmal M, Hayat M, Umar M, Ullah A, Ahmed I, Rahim K, Ali S, Bahadar S, Saleha S. Geographic distribution of hepatitis $C$ virus genotypes in Pakistan. Hepat Mon. 2014;14(10):1-5.

26. Idrees M. Development of an improved HCV genotyping assay for the detection of common genotypes and subtypes in Pakistan. J Virol Meth. 2008;150:50-6.

27. Afridi Q, Zahid N, Shabbir Z. Prevalence of HCV genotypes in district Mardan. Virol Journal. 2013;10

28. Idrees M. Common genotypes of hepatitis C virus present in Pakistan. Pak J Med Res. 2001:40:46-9.

29. Wilks S. The likelihood test of independence in contingency tables. Ann Math Statist. 1935:6:190-6.
30. Wilks S. The large-sample distribution of the likelihood ratio for testing composite hypotheses. Ann Math Statist. 1938:9:60-2.

31. Anwar I, Rahman M, Hassan U, labal M. Prevalence of active hepatitis C virus infections among general public of Lahore, Pakistan. Virology Journal. 2013; 10:351.

32. Daw A, Bouzedi E, Dau A. Geographic distribution of HCV genotypes in Libya and analysis of risk factors involved in their transmission. BMC Res Notes. 2015;8:67.

33. Ali S, Ali I, Azam S, Ahmad B. Frequency distribution of HCV genotypes among chronic hepatitis C patients of khyber pakhtunkhwa. Virol Journal. 2011;8

34. Inamullah IM, Ahmed H, Ghafoor U, Ali M, Ali L, Ahmed A. Hepatitis C virus genotypes circulating in district Swat of Khyber Pakhtoonkhaw, Pakistan. Virol Journal. 2011:8:16

35. Saleha S, Kamal A, Ullah U, Khan N, Mahmood A, Khan S. Prevalence of of hepatitis $C$ virus genotypes in district Bannu, Khyber Pakhtunkhwa, Pakistan. Hepat Res and Treatment. 2014;2014:1-5.

36. Khan S, Attaullah S, Ayaz S, Khan N, Shams S, Ali I, Bilal M, Siraj S. Molecular epidemiology of HCV among health care workers of Khyber Pakhtunkhwa. Virol Journal. 2011;8:105

37. Ahmad W, ljaz B, Javed F, Jahan S, Shahid I, Khan F, Hassan S. HCV genotype distribution and possible transmission risks in Lahore, Pakistan. World J Gastroenterol. 2010;16:4321-8.

38. Afridi S, Naeem M, Hussain A, Kakar N, Babar M, Ahmad J. Prevalence of hepatitis C virus (HCV) genotypes in Balochistan. Mol Biol Rep. 2009:36:1511-6.

39. Butt S, Idrees M, Akbar H, Rehman UI, Awan Z, Afzal S, Hussain A, Shahid M, Manzoor S, Rafique S. The changing epidemiology pattern and frequency distribution of hepatitis C virus in Pakistan. Infect Genet Evol. 2010;10:595-600.

40. Rasheed A, Ullah S, Naeem S, Zubair M, Ahmad W, Hussain Z. Occurrence of HCV genotypes in different age groups of patients from Lahore, Pakistan. Adv life sci. 2014;1(2):89-95.

41. Singh B, Verma M, Verma K. Markers for transfusion associated hepatitis in north Indian blood donors: prevalence and trends. Jpn J Infec Dis. 2004:57:49-51.

42. Rouabhia S. Hepatitis C virus genotypes in north eastern Algeria: a retrospective study. World J Hepatol. 2013:5:393-7.

43. Tabussam H, Amin M, Amanullah M, Tabussam S. Study is about the prevalence of the HCV disease and survival of HCV patients with associated factors in the population of district Multan. Pak J Pharm Sci. 2015:28(5):1807-10.

\section{Submit your next manuscript to BioMed Central and we will help you at every step:}

- We accept pre-submission inquiries

- Our selector tool helps you to find the most relevant journal

- We provide round the clock customer support

- Convenient online submission

- Thorough peer review

- Inclusion in PubMed and all major indexing services

- Maximum visibility for your research

Submit your manuscript at www.biomedcentral.com/submit 